\title{
The labyrinth of teacher leadership
}

\author{
Dennis Shirley ${ }^{1} \cdot$ Andrew F. Miller ${ }^{1}$
}

Published online: 28 January 2016

(c) Springer Science+Business Media Dordrecht 2016

Teachers find professional fulfillment when their students are learning at high levels. Teachers also know that their ability to enhance the quality of their profession is affected by their ability to create robust and intentional academic, social, and emotional learning experiences for students. These apparently simple goals prove difficult to achieve in practice. Developing teacher leadership to optimize pedagogy and curriculum appears to be a more labyrinthine process. Why is this?

One hypothesis is that teachers lack sufficient data about what their students know and do not know. This hypothesis gains special salience because educators and the public at large increasingly are living in what Mayer-Schönberger and Cukier (2013, p. 6) describe as the age of "big data." In this new era, consumers expect "personalized" services and respond accordingly. One-third of all amazon.com sales now are based on computer-generated algorithms, MayerSchönberger and Cukier report. Three-quarters of all Netflix recommendations for movies in the United States likewise come from data-driven suggestions. Visits to the doctor, the car repair shop, and the computer store all offer up a treasure trove of data to providers. With all other sectors transformed by the "datafication" (MayerSchönberger and Cukier 2013, p. 15) of the workplace, should not education also be part of this larger scientific and societal transformation?

The first article in this volume, by Amanda Datnow and Lea Hubbard, provides an empirical response to this line of inquiry. The authors examine international

Dennis Shirley

Shirleyd@bc.edu

Andrew F. Miller

andrew.miller.6@bc.edu

1 Lynch School of Education, Boston College, 140 Commonwealth Avenue, Campion Hall, Chestnut Hill, MA 02467-3813, USA 
research and find that the sheer availability of data often is not helpful for classroom teachers. This is because the rise of "big data" in education has been concurrent with the implementation of testing and accountability systems that have negative connotations for teachers in many jurisdictions. Even though there is no necessary relationship between data and these new systems, when they are combined educators experience the provision of data as a threat rather than as an opening for new lines of inquiry.

Datnow and Hubbard show that even the best sources of data cannot be used well by educators when their beliefs interfere with their capacities for improvement. "Data-driven decision making" is mediated through the powerful fulcrum of educators' experiences and values. Wise policy making will take those experiences and values into consideration through a process of sustained interactivity. In a recently published issue of the Journal of Educational Change, Peurach and Neumerski (2015) argue that this consideration from policy makers will "require tempering fiery, polemic political rhetoric; recalibrating expectations; and building and sustaining broad-based political support for a decades-long, inter-generational reform effort" (p. 413). Even when such wise policy making does take into account teacher beliefs, Peurach and Neumerski point out it can take up to 7 years for instructional infrastructure to be sustainably improved. Therefore, as Datnow and Hubbard argue, data should be used diagnostically as the twin issues of beliefs and capacity within a data-driven school setting are worked out among faculty and leaders over the course of several years. With data used properly for diagnostic rather than punitive purposes, its potential for improvement can be recovered and capitalized upon.

Yet the second article, by Corrie Stone-Johnson, provides sobering insights into the complexities of change at the school level and offers a different hypothesis to the root cause of the profession's stunted capacity to enhance student learning experiences. Stone-Johnson describes four schools in the suburb of a former Rust Belt city in the northeast United Sates in which low staff morale and poor student achievement are pervasive. In a highly original and conceptually sophisticated discussion, Stone-Johnson reviews the sociological literature on alienation and finds that educators' intensification and isolation have cascading effects that also impact the work of school counselors. Counselors in the U.S., unlike their colleagues in countries like Singapore and Finland, are not prepared as teachers first, and their detachment from the teaching and learning facets of schools places them at a predetermined institutional risk of marginalization. When faced with funding cut backs, counselors find themselves deployed to assist with test preparation and custodial activities that do not make proper use of their professional expertise. In policy contexts where student well being is ignored and enormous pressure is placed upon the academic purposes of schools, the roles of staff such as counselors become distorted.

Stone-Johnson finds that one way that teachers and counselors can respond to the pressures of workplace alienation in high-stakes accountability contexts is to reinvent their professionalism. There are voices within the recent research literature on teacher leadership that call for this kind of re-invention. This re-invention has been shown in past issues of the Journal to include a wide range of strategies. These 
include the use of collaborative inquiry (Butler et al. 2015), the development of teacher agency within district- and school-led professional learning communities (Wells and Feun 2013), the creation of space for teachers to negotiate the complex emotional investment brought about by educational policy changes (Saunders 2013), and the appropriation of "coopetitive" strategies where competition and cooperation are utilized for productive purposes (Muijs and Rumyantseva 2014).

Each form of re-invention focuses on the need for teacher agency to combat an alienation endemic in the profession. This can be undertaken in a myriad of ways. In one of the four schools Stone-Johnson studied, counselors evolved into curriculum designers who helped teachers to understand how they could be used in positive ways to enrich instruction. Such acts of reciprocal empowerment provide venues for new kinds of collaboration between educators and counselors that may be able to overcome the unfortunate distortions caused by intensification and isolation.

In schools in which teachers experience their work as line managers who fundamentally are in the business of implementing others' ideas, the sheer act of reclaiming their own potentials for reflection and independent action can contain what feels like a certain rebelliousness. The third article of this issue, by Kira BakerDoyle and Leif Gustavson, is entitled "Permission-Seeking as an Agentive Tool for Transgressive Teaching: An Ethnographic Study of Teachers Organizing for Curricular Change." The authors challenge the assumption that permission seeking must necessarily have a docile side. They show that five distinct "permissive moves" can help a faculty to advance rapidly and boldly towards a more studentcentered and responsive curriculum.

In recent years there has been extensive discussion of the "crisis in curriculum theory" (Young 2014, p. 101) or the "death of curriculum studies" (Snaza 2013, p. 154). While the argument has had many components, the overarching concern has been that the curriculum has become an afterthought as standards and testing have moved to the foreground of contemporary schooling. In both the second and third articles in this issue, however, Stone-Johnson, Baker-Doyle, and Gustavson contend that by exploring new ways of designing curriculum, educators can take decisive steps in overcoming workplace alienation and better respond to their students.

Designing new curriculum is important but systemic change requires adaptations in pedagogy as well. In the fourth article in this issue of the Journal of Educational Change, a team of six authors studied efforts in three charter schools in the United States to foster inquiry-based climates characterized by higher levels of classroom discussion. This article extends from a growing body of literature that examines innovative strategies used by charter and other schools to illuminate nuanced approaches to factors affecting student learning (e.g., Dobbie and Fryer 2011; Fryer 2011; Merseth 2009). In the analysis presented here, Cooper and her colleagues delve into the details of a change in pedagogical strategies. Only one of the schools, with a collaborative principal driven by a sense of urgency, was able to accommodate this shift. In the second school, the principal was focused on asserting her authority and viewed teacher leaders as enforcers of her policies. In the third school, the principal focused on acclimatizing her many new staff members and provided them with instructional tips rather than supporting professional 
development in such a way as to not only influence pedagogy but actually to change it.

Educational change, it would seem on review of the first four articles, is often fragmented. New data systems are introduced but without engaging teachers' beliefs and their capacities to use them to improve teaching and learning. High-stakes pressures produce not only alienated teaching but also alienated counseling, with no apparent contribution to student learning. When teachers do collaborate on curriculum redesign, they need to engage in "permissive moves" with one another rather than being able to have free give-and-take arguments with one another before reaching consensus. Changing pedagogies to enable students to participate more actively in discussions works in one school but falters in others although all of the studied schools have skilled teacher leaders on their staffs. Small wonder, then, that so many teachers become conservative and skeptical about change over the course of their careers, despite the negative consequences of these individualist attitudes for the aspirations of the profession as a whole. Their reaction is understandable as they endeavor to retain a measure of professional control over their own work.

One apparent resolution to these difficulties would be to conceptualize the change process differently. In the fifth and final article in this issue, Joan Conway and Dorothy Andrews elaborate "A School Wide Approach to Leading Pedagogical Enhancement: An Australian Perspective." They explain how imperative it is for educators to understand their schools as complex ecosystems and to work towards school wide pedagogies that tenaciously focus on student learning as the alpha and omega of every educator's professionalism. Such school-wide pedagogies have to be actively created and intentionally sustained through "parallel leadership" that empowers school principals and staff to optimize their decision-making authority while consistently focusing on harmonious relationships across all grade levels and content areas in a school.

Conway and Andrews describe in detail a Catholic school in New South Wales with which they have worked that exemplifies the potential of a school wide approach to pedagogy. Catholic schools throughout the world have a long history of enacting a mission rooted in social justice for the benefit of the students and communities served by these educational institutions (Bryk et al. 1993; Collins 2010; Denig and Dosen 2009). Conway and Andrews' article confirms this general finding about Catholic schools, and also shows the salutary effects of a school being willing to engage in school wide pedagogical development rooted in its distinctive mission. What is especially striking in their account is the emphasis on mutualistic relationships between principals and teachers that recognize separate spheres of expertise and authority. School wide pedagogy, when properly manifested, recognizes the individual educator's personal pedagogy, while also requiring the development of an authoritative pedagogy that is able to demonstrate meaningful contributions to student learning.

These five articles show that the fragmented process of enhancing the teaching profession is fraught with complications. Yet this process also provides opportunities for teachers to enhance student learning and to make teaching rewarding once again. Teachers today must find innovative ways to re-professionalize themselves 
through working in new ways with one another. This issue offers promising pathways out of the present labyrinth of developing authentic teacher leadership.

\section{References}

Bryk, A. S., Lee, V. E., \& Holland, P. B. (1993). Catholic schools and the common good. Cambridge, MA: Harvard University Press.

Butler, D. L., Schnellert, L., \& MacNeil, K. (2015). Collaborative inquiry and distributed agency in educational change: A case study of a multi-level community of inquiry. Journal of Educational Change, 16(1), 1-26.

Collins, M. C. (2010). Catholic schools and the immigrant community: A look backward and forward. Catholic Education: A Journal of Inquiry and Practice, 13(3), 392-402.

Denig, S. J., \& Dosen, A. J. (2009). The mission of the Catholic school in the pre-Vatican II era (1810-1962) and the post-Vatican II era (1965-1995): Insights and observations for the new millennium. Catholic Education: A Journal of Inquiry and Practice, 13(2), 135-156.

Dobbie, W., \& Fryer, R. G., Jr. (2011). Getting beneath the veil of effective schools: Evidence from New York City (Working Paper No. 17632). Cambridge, MA: National Bureau of Economic Research.

Fryer, R. G., Jr. (2011). Injecting successful charter school strategies into traditional public schools: Early results from an experiment in Houston (Working Paper No. 17494). Cambridge, MA: National Bureau of Economic Research.

Mayer-Schönberger, V., \& Cukier, K. (2013). Big data: A revolution that will transform how we live, work, and think. Boston: Houghton Mifflin.

Merseth, K. K. (2009). Inside urban charter schools: Promising practices and strategies in five highperforming schools. Cambridge, MA: Harvard University Press.

Muijs, D., \& Rumyantseva, N. (2014). Coopetition in education: Collaborating in a competitive envionrment. Journal of Educational Change, 15(1), 1-18.

Peurach, D. J., \& Neumerski, C. M. (2015). Mixing metaphors: Building infrastructure for large scale school turnaround. Journal of Educational Change, 16(4), 379-420.

Saunders, R. (2013). The role of teacher emotions in change: Experiences, patterns, and implications for professional development. Journal of Educational Change, 14(3), 303-334.

Snaza, N. (2013). The death of curriculum studies and its ghosts. Journal of Curriculum and Pedagogy, 11(2), 154-173.

Wells, C. M., \& Feun, L. (2013). Educational change and professional learning communities: A study of two districts. Journal of Educational Change, 14(2), 233-257.

Young, M. (2014). Overcoming the crisis in curriculum theory: A knowledge-based approach. Journal of Curriculum Studies, 45(2), 101-118. 